\title{
ALGUNOS ASPEGTOS DEL VENADO EN LA RELIGIÓN DE LOS MAYAS DE YUCATÁN
}

María Montolíu

El venado en la cultura maya, tanto antigua como contemporánea, ha desempeñado un papel importante, sobre todo en ciertos aspectos de la religión. El presente trabajo es un breve estudio de las diferentes funciones de dicho animal relativas a la cacería y al sacrificio rituales; a su relación con los dioses del panteón maya y a su papel como símbolo de la fertilidad.

Este trabajo se refiere particularmente a los mayas de Yucatán, prehispánicos y contemporáneos; pero añadiremos datos de otros pueblos mayas con la finalidad de hacer comparaciones y completar los materiales que presentaremos.

Representaciones de venados en materiales arqueológicos

En la región de Cotzumalhuapa (Bilbao, Guatemala), se encontró un monolito perteneciente al Clásico tardío que representa un venado antropomorfo. $\mathrm{El}$ venado está en actitud de entregar una vaina de cacao a un personaje que se encuentra recostado, que por su aspecto puede ser un dios. En la parte superior del grabado, aparecen cinco círculos y el signo de "casa". Parsons dice que la vaina de cacao simula ser quizá la ofrenda de un corazón (1969, II, : 116), (Fig. 1). Sin embargo puede tratarse de la representación del propio dios del cacao en el acto de recibir una ofrenda de manos del venado que actuaría como mensajero de los dioses.

En el Templo de las Inscripciones de Palenque se encontró un pedazo de estuco con la forma de una cabeza de venado que tiene como particularidad la huella de un pie humano grabada en el lugar que correspondería al ojo '(Ruz, 1958, X: 216), (Fig. 2). La pieza de estuco proviene de la azotea del edificio.

Entre las representaciones más importantes de venados en cerámica, encontramos el vaso policromado de Río Hondo (Belice), 
en el que aparece un ciervo con pies y manos de hombre. Las manos están atadas y el venado mira hacia arriba al sitio donde se encuentra otro animal con antenas similares a las de un insecto. En el grabado de la izquierda aparece un colibrí y también un zopilote. En la parte superior se encuentran dos insectos no identificados. Uno de ellos, el que está sobre un colibrí, tiene el signo Akbal en su cuerpo, signo asociado con la noche y la oscuridad. Por otro lado, en la parte superior vemos una serie de glifos aún no identificados, de los cuales, el segundo, comenzando por la derecha, está relacionado con la Luna. El zopilote se representa también en la parte superior de otro dibujo que es una planta con dos flores. La planta

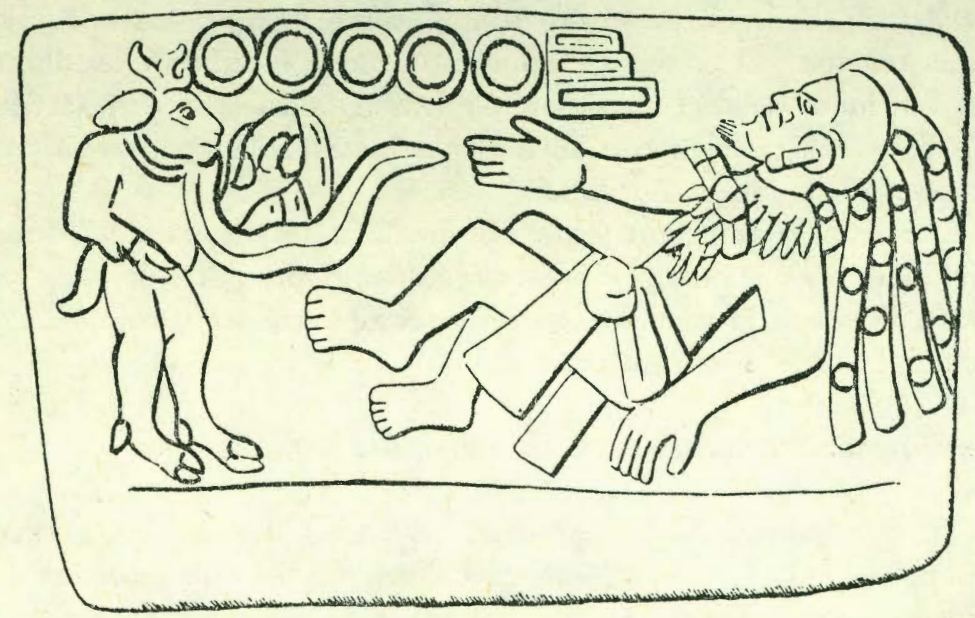

Figura 1. Monumento 14, Cotzumalhuapa, Bilbao, Guatemala. (Parson, 1969, II,: 250).

tiene en su parte inferior el signo Ahau, asociado al Sol. El vaso pertenece al Clásico tardío. Thompson piensa que la escena del vaso se relaciona con un pasaje del antiguo mito mopán (Belice), en el cual el Sol se oculta en el cadáver de un venado para atrapar a un zopilote que había raptado a la Luna (Thompson, 1939: 150), (Fig. 3). Tomando en cuenta que en el vaso hay símbolos de la noche y del día, podríamos pensar que se trata del Sol en su recorrido por el cielo, pues el venado, el zopilote y el colibrí se relacionan en el corpus de mitos, con el astro. Volviendo al dibujo, podemos observar que también contiene insectos y signos lunares. Esto último puede aludir al hecho de que la Luna representa a la madre de los 
insectos en el mito mopán. Estos, cuando aparecen asociados a la Luna, significan, en algunos casos, muerte.

En Yucatán se encontró un vaso perteneciente al Clásico tardío, que se conoce con el nombre de vaso de Calcehtoc, cuya procedencia es incierta. La escena que representa parece referirse a un tema mítico o religioso. A la izquierda aparece un venado que lleva sobre

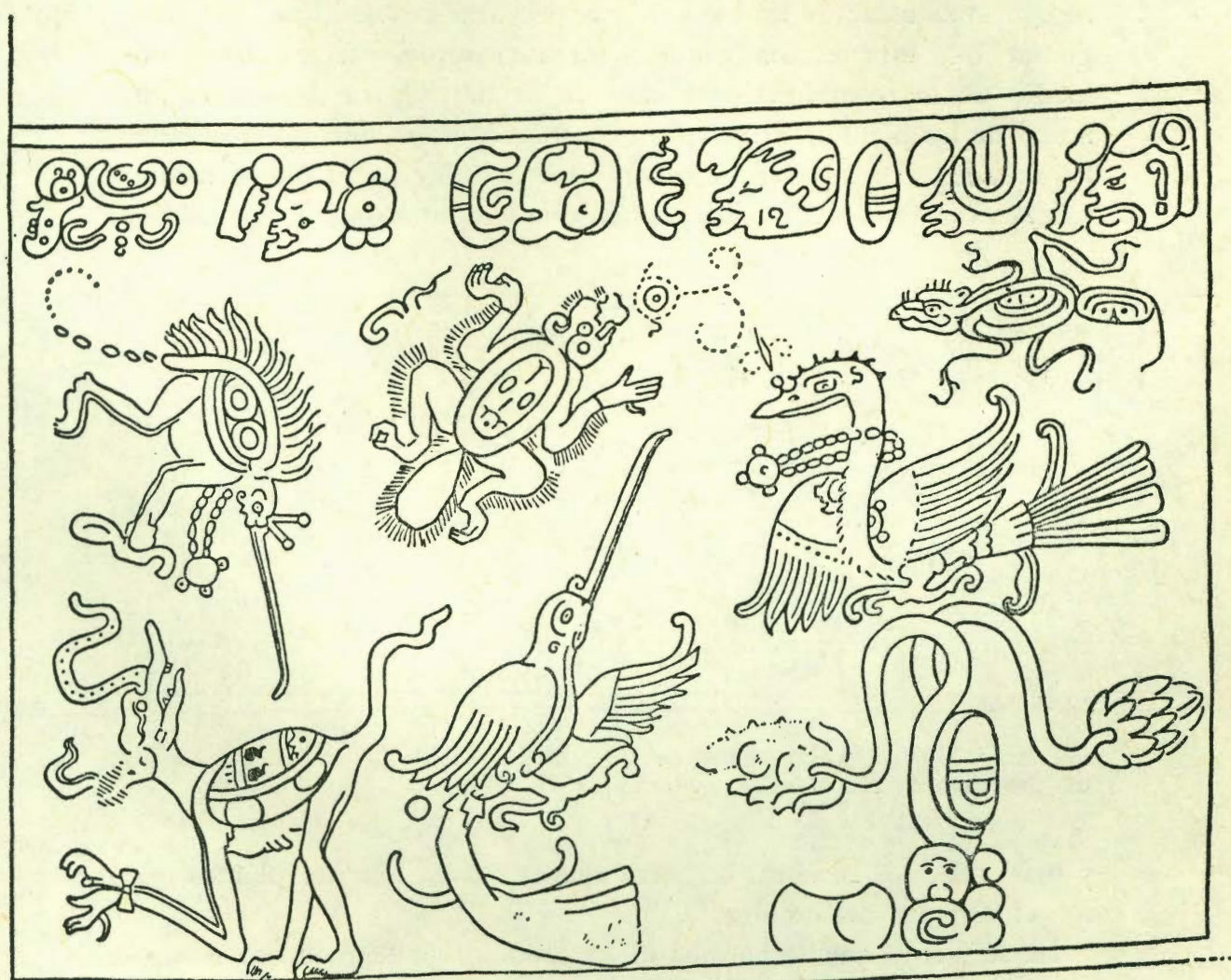

Figura. 3. Vaso policromado de Río Hondo, Belice. (Thompson, 1939: 151).

el lomo una manta con los símbolos de la muerte. Cerca del animal se encuentra un personaje sosteniendo una lanza en una mano y un cuerno en la otra. Otro personaje que se encuentra delante del ciervo, coge uno de los cuernos del venado que en ese momento se desprende. Este individuo porta también una lanza. Enseguida, a la derecha se halla una ceiba, en cuyo tronco se observa un rostro humano. Sobre las ramas del árbol están sentados dos individuos, y 
abajo se encuentran dos personajes antropozoomorfos, también sentados, con la forma de un venado semihumano. Uno de ellos tiene el cuerpo cubierto de vendas. En el tronco del árbol se enrosca una serpiente (Morley, 1972: 417).

La relación que hay entre el hecho de que el venado pierde la cornamenta hacia el mes de marzo, y el de que es la época en que se comienza a labrar los campos y a preparar las siembras, nos hace pensar que esta escena pudiera ser una representación del fenómenos de la fecundidad-fertilidad de la tierra y de la renovación anual de las plantas. El venado que aparece en el instante de perder los cuernos, está representado conforme a la ley de la magia simpatéticà; es decir, de la misma manera que el animal pierde sus cuernos

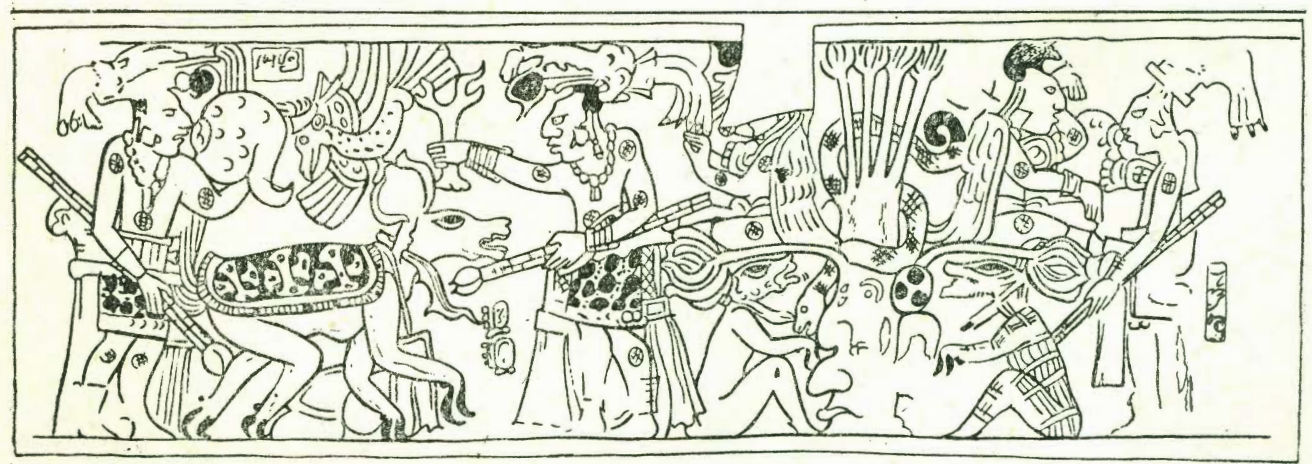

Figura. 4. Vaso policromado de Calcehtek encontrado en Yucatán, pero de procedencia desconocida. (Morley, 1972: 417).

y más tarde los recobra, la tierra renueva cada año las plantas que son el sustento del hombre.

La serpiente que se enrosca en el árbol probablemente se relaciona con los dioses de la tierra que propician la fecundidad de ésta. Los venados que están bajo las ramas de la ceiba, pueden estar relacionados con el sacrificio de dichos animales y la propiciación de las buenas cosechas .(Fig. 4).

El vaso de Actum Balam (Belice), perteneciente al Clásico tardío, representa a varios personajes en actitud de atacar a un venado. Uno de los animales del dibujo es un venado sobrenatural que lleva en la boca un ramo de flores y sobre su lomo a un personaje que se sujeta de los cuernos de dicho animal. Otro personaje más que aparece dibujado atrás, se halla arrodillado siendo sus características las de un enano (Pendergast, 1966: 154-55), (Fig. 5). 
El venado en trance de ser atacado, aparece en un evidente contexto de cacería; pero el que se sostiene en dos patas y en cuyo lomo carga otro personaje, tiene un aspecto sobrenatural. Recordemos que estos animales tienen protectores y éste es un ciervo mítico. Es probable que la escena se relacione con el protector de los venados.

En el vaso de barro de Ixtapa (Chiapas) (Anton, 1968: 81); perteneciente al Clásico tardío, se presenta una escena mítica en la que vemos varios animales relacionados con los dioses. Anton afirma que se trata de una escena de cacería, pero una vez más, podemos observar que presenta más bien un carácter mítico, (Fig. 6). En el grabado, a la izquierda, se encuentra un personaje que carga un tigrillo cuya cabeza está adornada con flores; el tigre puede representar al

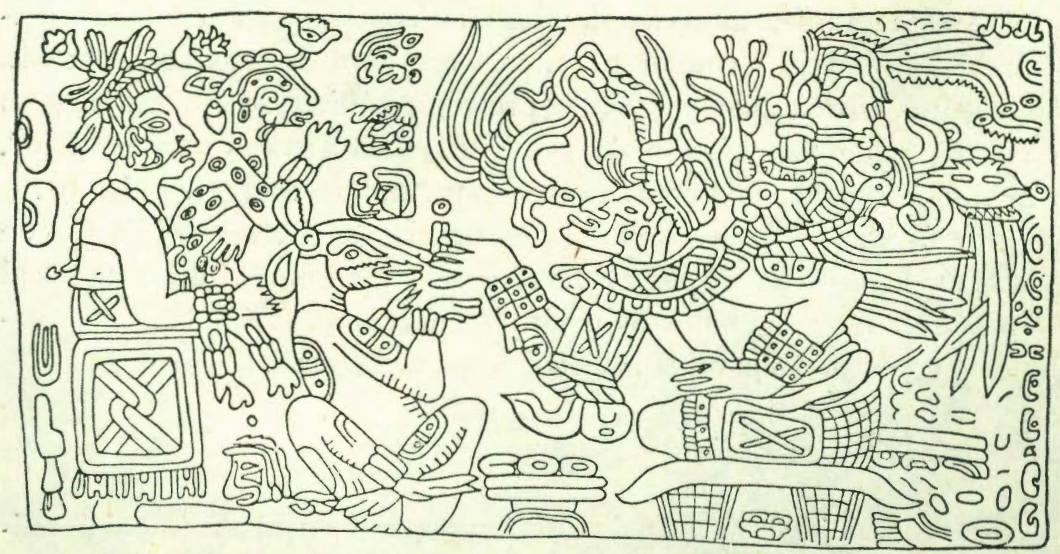

Figura. 6. Vaso de Barro de Ixtapa, Chiapas, (Anton, 1968: 81).

"Señor que protege los bosques". Enseguida se observa un venado sentado con las piernas cruzadas, en actitud de recibir, de manos de un individuo, una ofrenda o un platillo. A sus pies están otros platillos con alimentos. El personaje que hace la ofrenda al venado se encuentra ataviado con lujo. La escena puede representar las ofrendas que se deben al "dueño de los animales"; deidad protectora de la fauna. Los animales del dibujo tienen el aspecto de seres sobrenaturales, dados sus atavíos.

En el Museo Nacional de Antropología e Historia, existe un plato policromo, perteneciente al Clásico tardío de Yucatán que representa sin duda una escena de cacería. En el centro está un hombre en cuclillas que sostiene un venado ya cazado, en cuya cola se posa un ave de pico largo. Alrededor del plato aparecen tres cazadores de 
venado, con disfraces de dicho animal. Cada cazador lleva una bramadera y se encuentra en actitud de seguir a los venados que llevan la cola en posición vertical, lo que indica que van corriendo. Los cazadores tienen una parte de su disfraz pintada de negro y uno de los venados que se encuentra alrededor del plato, luce también la mitad de su lomo pintado del mismo color. Otro de los cazadores de alrededor del plato, lleva sobre el tocado un ave similar a la que se posa en la cola del venado central. Esta escena quizá represente la cacería del animal que se efectúa con la ayuda de una bramadera, la cual sirve para engañar con su ruido a los venados, pues ésta imita a la hembra en brama. El animal suele acudir al oir este sonido. El negro de los trajes de los cazadores y del lomo del animal se relaciona tal vez con la muerte. Las aves que aparecen en el dibujo probablemente aluden al hecho de que en Yucatán, existe un pájaro llamado "arrendajo", similar a un cuervo; pero con manchas azules. La gente afirma que el "Zip" (protector mítico de los venados en Yucatán, que tiene forma de venadito), "llora como el arrendajo". El sonido del arrendajo se traduce por "ppapp-ppapp". (Fig. 8).

Por último, mencionaremos la existencia de silbatos de barro con escenas de cacería; donde el cazador se representa dando muerte al venado con un cuchillo de piedra (Thompson, 1963: 76). Probablemente estos silbatos se utilizaron para la caza.

\section{El venado en los códices mayas}

El venado jugó un papel muy importante en el ceremonial religioso. Prueba de ello son las numerosas representaciones de venados y de ofrendas de éste animal que aparecen en los códices. El venado se relaciona con diversos dioses en dichos códices; con otros animales y con fenómenos como la lluvia, la fertilidad y la sequía.

Las características de los venados pintados en los códices son las siguientes: cabeza y orejas largas, cola larga y vertical, (posición de carrera); cuernos y presencia de incisivos bajos. Algunos venados presentan la glándula lagrimal exageradamente desarrollada. Lo anterior se relaciona con la idea que tienen los mayas respecto a que "el venado debe de morir llorando" porque sus lágrimas, "atraen las gotas de agua del cielo" (Tozzer, 1910: 348). Esto a su vez asocia al venado con la fertilidad de la tierra.

Los tipos de venado que aparacen en los códices son principalmente de la especie Odoicoleus yucatanensis, comúnmente llamado ke en Yucatán y de la especie Mazama pandora, conocido como gamo yucateco. 
El venado como pieza de ofrenda para los dioses aparece en el Códice Madrid en el que además hay varias escenas de cacería (láminas 38 a 40); en el de Dresde donde aparecen cabezas, caderas y patas de venado (láminas $28 \mathrm{c}$ y $35 \mathrm{a}$ ) y en el Códice París, en el cual las ofrendas son sobre todo cabezas (lámina 10).

En el Códice Madrid (69b), el dios B, deidad de la lluvia y la fertilidad, tiene colocadas, como ofrendas, cabezas de venado.

$\mathrm{El}$ venado directamente relacionado con la cacería aparece en el Códice Madrid (38-40); los cazadores muestran las formas más usuales para cazar venados. En el mismo códice, (92a) observamos un venado pequeño dentro de una trampa. Como esta escena existen otras varias en los códices, que enseñan la manera de atrapar estos animales. Una de las trampas que se encuentran más representadas consiste en un cordel sujeto a una rama; esta trampa se coloca en las veredas que llevan a algún bebedero. Cuando el animal pasa por allí y la pisa, resulta atrapado por el cordel. (Madrid, 44a, 45b, $46,47$ y $48 \mathrm{~b})$. El objeto de las representaciones de trampas fue probablemente mostrar las técnicas de cacería.

En el Códice Madrid (105b 108a) las ofrendas de venado están relacionadas con el cultivo de las abejas; es probable que estas ofrendas hayan sido hechas para pedir "abundancia de miel".

En el códice mencionado, el alacrán se encuentra asociado con el venado, (39c). Observando la parte superior del grabado, vemos un venado con cola de alarcrán, la cual termina en forma de mano y ésta sostiene un puñal. El puñal parte en dos al ciervo dibujado en la parte inferior. El venado se relaciona también con el alacrán en las láminas $44 \mathrm{~b}$ y $44 \mathrm{c}$ del códice. En esta ocasión, la cola del alacrán muestra una mano que sostiene la cuerda que atrapa a un venado por la pata. Al respecto, Thompson comenta que:

la palabra yucateca para escorpión es zinnan, cuyo participio zin, significa "estar listo a lanzar o flechar". Esto explicaría la relación entre la cola del alacrán, el puñal que se clava en el venado y el sacrificio del animal. En tzeltal y tzotzil, la palabra para escorpión es $t z e c$, que en yucateco significa "castigo o pena". Por otro lado, el glifo Manik se representa por una mano. Es probable que se refiera a la misma que aparece en la cola del escorpión. Los significados tanto de Manik como de Moxic se desconocen; pero el diccionario de Pío Pérez, indica para moch muñeca, dedos o patas de pájaro... (Thompson, 1971: 76-77).

De lo anterior podemos deducir que siendo zinnan la palabra para escorpión, zin "estar listo a lanzar o flechar" y tzec, "pena o cas- 
tigo", la imagen del escorpión con la cola que termina como mano y la mano asiendo un cuchillo, indicaría la acción de un sacrificio preciso y penoso. Por otro lado, los nombres de los días: Manik, (calendario yucateco), palabra que no tiene una traducción precisa por el momento, pero que está relacionada con la cacería; Mochic, (tzotzil y tzeltal) que significa muñeca; y Ceh o Cieh, (nombres relacionados con el venado en los calendarios jacalteca y quiché respectivamente); están asociados al sacrificio del venado y a la rogativa de "abundancia de animales en las cacerías".

Otro animal relacionado con el venado en los códices es la serpiente. En el Madrid (29c), se le representa sentado en el borde de una curva, que simula una serpiente azul. La serpiente parece figurar una línea de agua; el venado, la serpiente y el agua son símbolos de la fecundidad de la Tierra. (Tozzer, 1910: 351).

El pecarí y el venado se hallan asociados a el agua en el Códice Madrid. Estos animales se encuentran sentados cerca de una diosa de cuyo cuerpo brota agua. Esta escena puede simular un diluvio; los animales están relacionados con la muerte y las inundaciones terrestres.

Insistiendo en la asociación del venado y la fecundidad, observamos en el Códice Madrid (82d) que el venado está sobre una estera, frente a una figura femenina, en acción de cohabitar, según Tozzer. En el Códice de Dresde (13c), un ciervo de aspecto femenino se encuentra en la misma posición; esta vez en acción de cohabitar con el dios M, (de la guerra) (Tozzer, 1910: 350).

El hecho de que el venado cohabite con una figura femenina nos recuerda que en los mitos mopanes y kekchíes dicho animal le formó la vagina a la Luna, para que ésta pudiese cohabitar con el Sol. El Sol y el venado se relacionan recíprocamente en tales mitos. (Thompson, 1939: 131).

\section{Dioses mayas relacionados con el venado y la cacería}

Tanto en los códices como en las fuentes de la historia maya, el venado se presenta relacionado con diversos dioses: en el Códice de Dresde (41c), aparece cargando sobre su lomo al dios B (dios de la lluvia y la fertilidad); está pintado de rojo y en posición desfalleciente, acaso por la sed. El color rojo está asociado simbólicamente con el oriente, el fuego, el calor y la sequía. Es probable que en esta representación, el venado, símbolo de la sequía pero a la vez de la tormenta transporte a uno de los chacoob rojos, propiciadores de la lluvia. 
Entre los nahuas, el venado o mazatl simboliza también la sequía y el fuego. En el Códice Bolonia (4), una cabeza de ciervo representa unas llamas (Spranz, 1973: 462). En el de Dresde (41c) el venado se relaciona con la deidad de la lluvia y la fertilidad. Para los nahuas, Tláloc, (dios de la lluvia), es el señor del signo de los días Mazatl (venado). (Spranz, 1973: 462).

En el manuscrito de Dresde, el dios B se relaciona con las cuatro ofrendas conocidas para pedir "abundancia de cacería" y que son: una semilla de maíz o una pieza de caza; un pez, un lagarto y la cabeza de un zopilote. En el mismo Códice, la deidad de la lluvia tiene una obvia conexión con los cuatro puntos cardinales y con sus colores respectivos, pero en relación con la posición de las ofrendas para la petición aludida (Schellhas, 1904: 17). Esto reafirma una vez más la relación que existe entre el dios $\mathrm{B}$ y la cacería.

El dios $\mathrm{L}$ estudiado por Thompson es una deidad terrestre puesto que ostenta los símbolos de los dioses de la tierra. Su glifo está formado por un pez y el prefijo Imix (Schellhas, 1904: 17). Según Thompson, este dios se identifica con la deidad denominada Lahun Chan o "Diez Cielo", que es, a su vez una manifestación de Venus. La cabeza de "Diez Cielo", se ha querido identificar con la de un jaguar: esto asociaría a la deidad con el "Señor del bosque", que protege en general a los animales. En el Katún de la creación en la versión de Maní, el dios "Diez Cielo" se llama "Nueve Montaña" (Thompson, 1971: 218-19). Esto relaciona, una vez más, al dios L con las montañas y probablemente también con el "Dueño de los animales". Entre los mayas actuales de Belice, Venus es el dios protector de los animales (Thompson, 1930: 119-32). El dios L no se relaciona con el venado directamente, pero sí con otros animales que viven en las montañas.

El dios M de la clasificación de Shellhas es la deidad de la guerra. Se le relaciona con el venado, ya que aparece en el Códice Madrid con un tocado que lleva los cuernos de este animal (Schellhas, 1904: 36). Una vez más, estamos en presencia de un dios ataviado como cazador, aunque su actividad sea la guerra. EI dios $\mathrm{M}$ se representa en dicho Códice con arco y flechas. Esto nos recuerda que en Mesoamérica, algunos dioses celestes se pintan como cazadores. Soustelle menciona a Mixcóatl y a Huitzilopochtli; que aparecen armados.con arcos y propulsores, (atlatl), y con flechas. Algunas veces llevan un morral de hilo. Estos dioses son propios de los pueblos bárbaros que invadieron la meseta central. En cambio, en el panteón mexicano, al momento de la Conquista existían deidades de la tierra, del maíz 
y del agua; entre estos, Tláloc. Soustelle añade que debemos distinguir entre los dioses mexicanos "dos líneas": los de la agricultura y los cazadores; aunque no se puede trazar entre ellos una línea divisoria precisa, ya que debido a la influencia que ejercieron los unos sobre los otros sus verdaderas identidades resultan ambiguas (Soustelle, 1959: 62).

Los dioses $\mathrm{R}$ y $\mathrm{Q}$ estudiados por Thompson, se relacionan con el venado, su cacería y su sacrificio. El dios $\mathrm{R}$ se identifica por la línea de su cara que tiene la forma de un signo Caban; lo que asocia esta deidad con la Tierra. Según Thompson:

...ésta deidad tiene carácter benevolente y se asocia de alguna manera al maíz y al venado. $\mathrm{El}$ dios $\mathrm{R}$ aparece con el número once ante él, estando asociado por lo tanto, con la deidad de este número. A su vez el dios del número once, patrón del día Manik en el calendario yucateco, se encuentra claramente en un contexto de "venado y cacería". El pronóstico para este día, en la lista de augurios de Kaua, menciona a "aquel de las colinas"; dios que guarda la tierra, la montaña y el venado. Entre los quichés, este mismo día es el indicado para rezarle a la montaña y pedirle animales. La cabeza del dios del número once, aparece representada en muy pocas ocasiones, pero lleva algunas veces el signo Caban, un círculo especial y un rizo, signos característicos de las deidades luni-terrestres. El dios R, se representa también en algunas ocasiones con el signo Caban, y este signo aparece ocasionalmente sobre el glifo del dios del maíz. (Consultar Códice Madrid, 60b, 65a y $97 \mathrm{~b})$. Como el dios $\mathrm{R}$ aparece repetidas veces con el número once ante él, podemos suponer que el número es parte de su nombre. Aunque los dioses incorporados a los números son raros, el dios más cercano al número once es Buluc-Ch'abtan u "Once Castigo". Este dios se relaciona con el día Siete Zip, fecha en que se pide perdón por el derramamiento de sangre de los animales que se cazan durante todo el año. (Thompson, 1971: 135).

En realidad el dios $\mathrm{R}$ de Thompson, es la deidad que está más relacionada con el venado y su protección, aunque no podemos saber si su función específica fue proteger a estos animales en particular o a toda la fauna en general.

En cuanto al dios $\mathrm{Q}$, Thompson nos dice:

...éste dios se relaciona con el sacrificio y la muerte. Su origen es caledárico y en ocasiones aparece ante él el número diez, que lo conecta con la deidad de la muerte. La deidad $Q$ se asemeja al dios Xipe del centro de México; ya que ambos dioses presentan similares marcas en la cara, portan por igual cuchillos de punta de piedra y presiden las ceremonias de sacrificio, en compañía del 
dios de la muerte. Así, el dios $Q$ parece ser la deidad de los sacrificios; siendo una prueba de ello el hecho de que esta deidad se conecta con el glifo del día Manik (calendario yucateco), glifo que parece representar una mano, probablemente la que empuña el cuchillo de los sacrificios... (Thompson, 1971: 76).

El dios $Q$ se halla relacionado también con los días Etznab (Yucatán) y Técpatl (centro de México). Este último nombre significa "cuchillo de pedernal". Dichos días están asociados a los sacrificios у a los instrumentos para realizarlos. (Thompson, 1971: 87).

Veamos ahora algunas referencias a los dioses que se relacionan con el venado en diversas fuentes de la historia maya.

Landa habla de la cacería del venado diciendo que la gente se avergonzaba si lo mataba y temía comerlo. Esta afirmación permite deducir que los venados eran vistos de manera especial, lo que coincide muy bien con el hecho de que hoy en día los mayas celebran ritos para cazar animales, especialmente venados. Más adelante, Landa dice que el día Siete Zip, lo mismo que un día del mes de Zac, se efectuaban ritos en honor de los dioses de la cacería. En la ceremonia estaban presentes los dioses de la medicina, Ixchel, Itzamná y otros. Los sacerdotes comenzaban por hacer exorcismos, comu era la costumbre, a fin de ahuyentar a los malos espíritus. Después se invocaban a los dioses de la cacería Acanum, Zuhuyzib y Zipitabay. A continuación, sigue Landa, se encendía el fuego y todos sacaban una cabeza de venado y sus flechas, para que uno de los sacerdotes las untara con betún azul y se hacían un orificio en la lengua para pasarse la hierba $a c$, en señal de penitencia Tozzer, 1941: 154). Al final tenía lugar una borrachera ritual.

Los nombres de los dioses mencionados por Landa pueden significar: Acanúm, "El que gime o brama", de acan gemir, bramar, llorar, etc. El nombre de éste dios nos recuerda que el protector de los venados entre los yucatecos actuales llora y gime cuando mira a sus congéneres en peligro. Zuhuyzib, "El que es virgen y concede dones", proviene de $z u h u y$ virgen y $z i b$ o zip, ofrenda; y Zipitabay, "La que concede dones mediante mecates", de $z i b$ ofrenda o don y $t a b$, hilo - mecate. Es posible que el nombre Zipitabay, tenga alguna relación con la denominación de la diosa Xtabay, patrona de los que se ahorcan mediante mecates, y por lo tanto deidad asociada a las trampas para los venados, hechas precisamente con cordeles. Tanto Zipitabay como Xtabay, muestran cierta afinidad con la diosa Ixchel. patrona del tejido.

Bernal Díaz del Castillo menciona en su obra a un grupo étnico 
que habitó el sur del estado actual de Campeche y parte del Petén. Este grupo se conocía por el nombre de los quejaches, de $k e$, venado y kaak, abundancia; por lo tanto, es "lugar donde abunda el venado". En efecto, no mataban a dichos animales, ya que recordaban que un día su dios se les apareció en forma de venado (Díaz del Castillo, 1933: 344-5).

En la Relación de Zotuta y Tibolón perteneciente a las Relaciones de Yucatán, se describe un dios de los venados, al que se ofrecían partes del animal y se le untaba la cara con la sangre de los ciervos sacrificados. Cuando no se conseguían buenas piezas, el cazador regresaba y acometía a patadas al ídolo, diciéndole que no servía para nada (Relación de Zotuta y Tibolón, 1898: XI: 93).

En el Chilam Balam de Chumayel, específicamente en el "Libro de los enigmas", se ordena lo siguiente: "Traédme aquél que dá cornadas en el cielo y aquél que tiene los dientes encorvados..." (Roys, 1967: 127). Aquí se hace referencia al venado y al topo. El venado se relaciona con el cielo.

En el mismo libro de Chumayel, en el capítulo de "Los linajes", se habla de los "Señores de los Venados": ... acabado el Katún en que fueron traídos los deshonestos, se vio la muchedumbre de guerreros. Y fueron cogidos por los Señores de los venados... (Mediz Bolio, 1973: 122).

En el Ritual de los Bacaboob (Roys, 1965: 156-58), se menciona un dios relacionado con la cacería, que a la vez se asocia con los encantamientos para curar úlceras: su nombre es Ah Uuc Yol Zip, "Señor Siete Corazón Ofrenda". Este nombre proviene de $a h$, "señor", uuc o vuc, "siete", yol, "corazón" y zip "ofrenda o don". El dios puede estar relacionado con el día Siete Zip que menciona Landa, en la cual se invocaban a varias deidadas de la cacería. Hay otro dios que se nombra en el Ritual de los Bacaboob; Ix Meklah Zip, "La que porta las ofrendas", de $i x$, prefijo femenino, mekla, "cargar, portar, o llevar", y sip o zip "ofrenda o don". Estos dioses debieron ser también patronos de la cacería.

Por otra parte, en el mismo Ritual, encontramos una oración que no se ha podido traducir debido a lo complejo de su lenguaje y qúe se llama "palabras para llamar al venado". Con la ayuda del maestro Otto Schumann, dedujimos lo siguięnte del texto: la oración habla de ofrendas o dádivas; invoca al poderoso "Señor del viento blanco"; habla del pez blanco y pide flores blancas que relaciona con las patas del venado (Roys, 1965: 113). Es probable que se trate de una oración para invocar al dios de lós venados y solicitarle bue- 


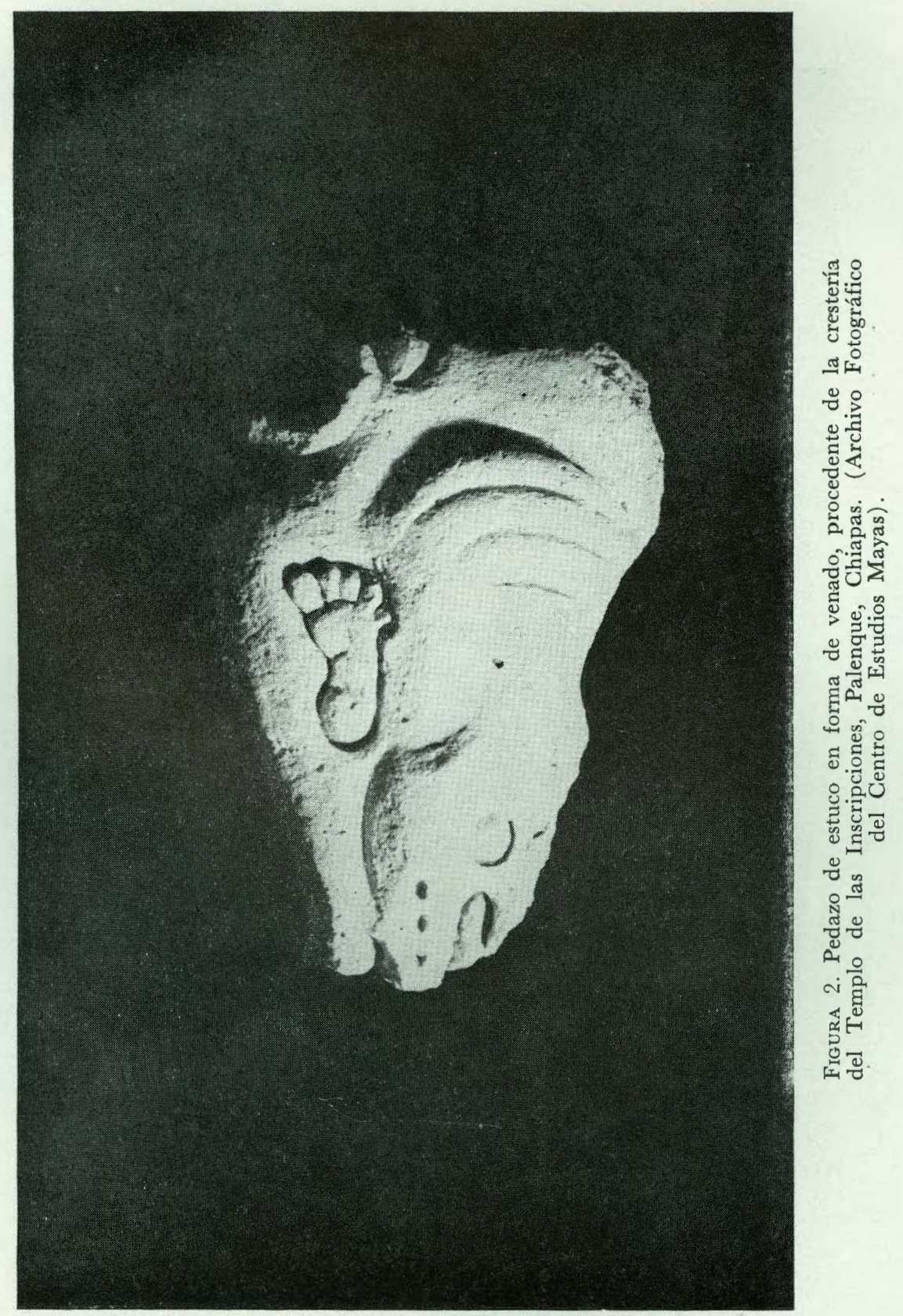

Estudios de Cultura Maya. Vol. X, 1976/7

Instituto de Investigaciones Filológicas/ Facultad de Filosofía y Letras Centro de Estudios Mayas, UNAM 


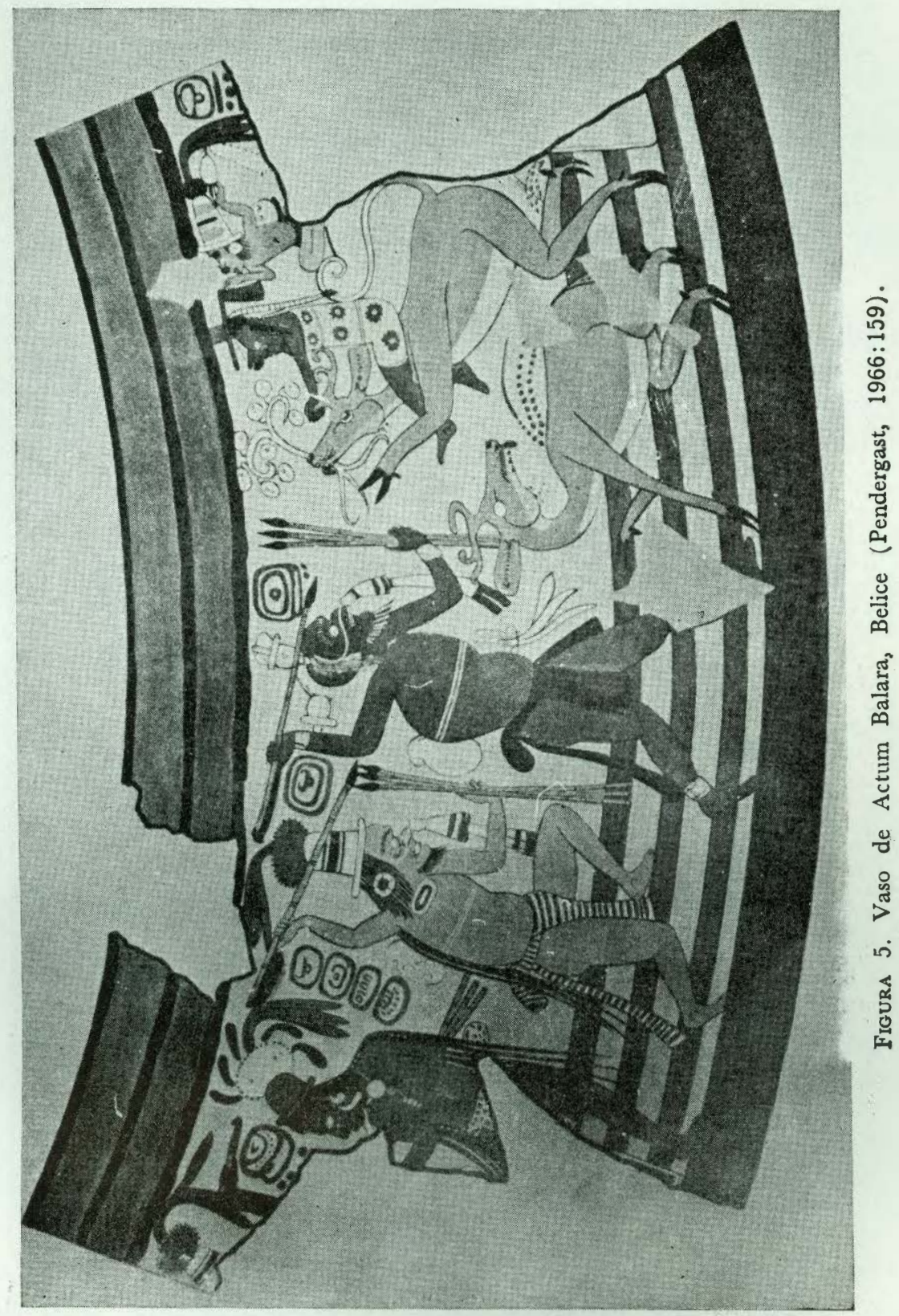

Estudios de Cultura Maya. Vol. X, 1976/7

Instituto de Investigaciones Filológicas/ Facultad de Filosofía y Letras Centro de Estudios Mayas, UNAM 


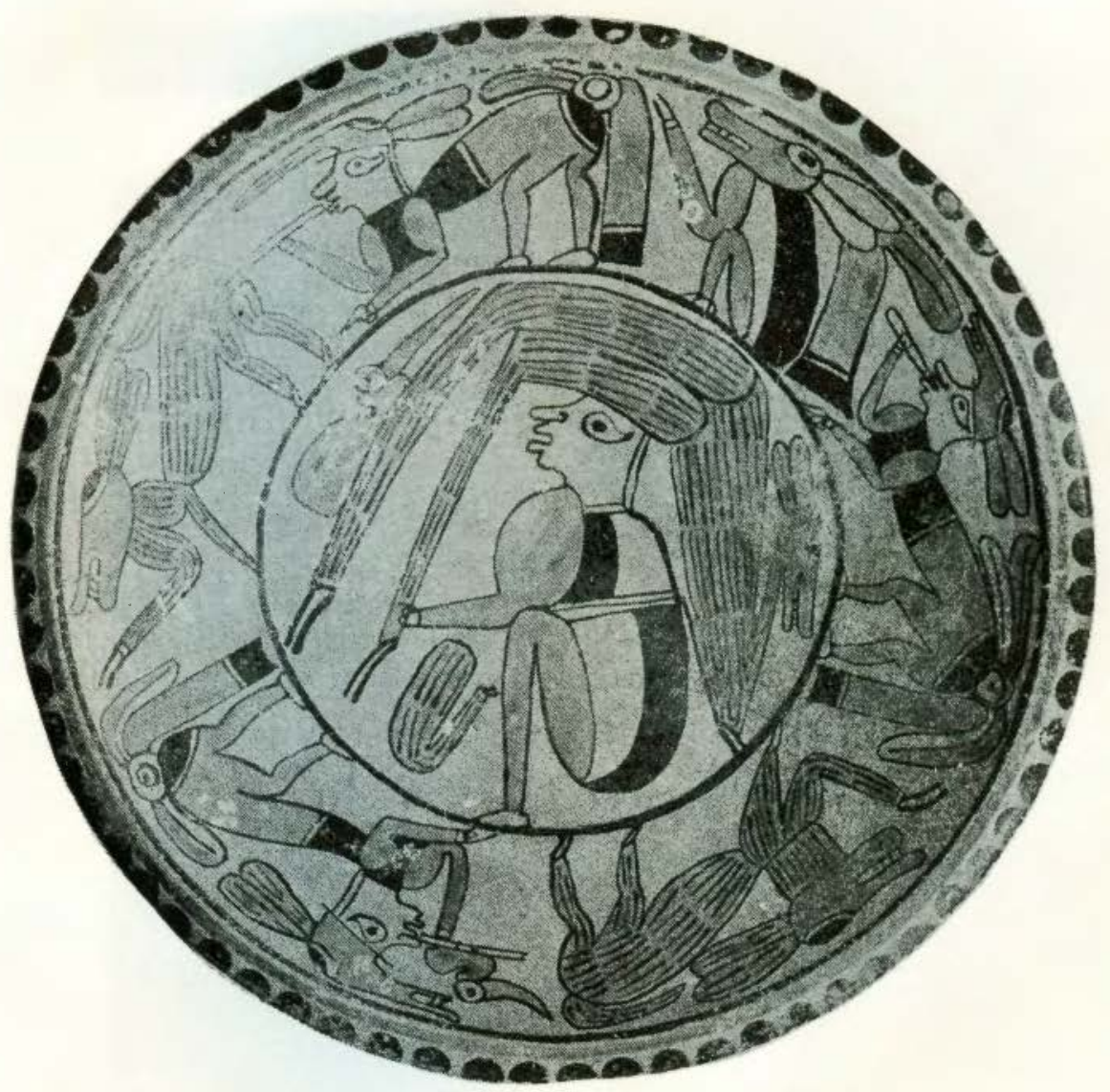

Figura 7. Vaso policromado de Yucatán, Museo Nacional de Antropología e Historia, México. (Archivo fotográfico INAH). 
nas piezas de cacería. Las patas del venado fueron vistas como flores blancas por los mayas prehispánicos. El venado aparece relacionado también con el viento.

Respecto al problema del venado en Guatemala, el Lic. Palacio, en sus "Cartas a Felipe II", relata la ceremonia siguiente: los cazadores cogían un venado y lo llevaban al cu que estaba en la periferia del pueblo. Allí lo mataban ahogándolo y le sacaban toda la sangre, la que se salaba para ser consumida después. El venado ya destazado se cocía en una olla, mientras se efectuaba un baile. El sacerdote principal tomaba la cabeza del animal y los ayudantes las patas. El corazón se quemaba con uli y copal en honor del dios de la pesca y la cacería. Después llevaban a la casa del sacerdote principal la cabeza del venado y éste se comía la cabeza tostada. Los demás sacerdotes se comían el resto del animal delante del ídolo (Relación hecha por el Lic. Palacio... 1886, IV: 31).

De lo anterior podemos deducir que se celebrara una especie de comunión al ingerir el venado sacrificado y santificado, con objeto de congraciarse con el dios protector de esa especie y para pedirle que concediese buenas piezas de cacería.

En el Popol Vuh se menciona a un dios relacionado con el venado, en el pasaje referente a la despedida de los cuatro primeros sacerdotes de su pueblo, leemos lo siguiente: ... ellos deben partir ya que el "Señor de los Venados" está manifiesto en el cielo... (Recinos, 1968: 125-26).

En otro lugar del Popol Vuh se hace referencia a la piel de venam do, la cual representa al dios Tohil: ... así pues, la piel del venado será nuestro símbolo que manifestaréis ante la tribu. Cuando se os pregunte, ¿dónde está Tohil?, presentaréis el venado ante sus ojos. (Recinos, 1968: 126-7). Respecto a esto, es interesante advertir lo que comenta Thompson al describir la relación de los días, Muluc, Mulu, Toh y Tcho, (de los calendarios yucatecos, tzeltal o tzotzil, quiché e ixil respectivamente):

El día Muluc, equivale al día Atl en el calendario mexicano. El símbolo para este día, es el jade y la diosa del agua se denomina, "La de la falda de jade". Por lo tanto el día está relacionado con las deidades del agua. La palabra Muluc, que viene de la raíz tzeltal mul, significa agua escondida. Por otra parte, la raíz mul se relaciona con el verbo, congregar o colectar "agua". Lo anterior sugiere la relación de esta palabra con agua o nube. La palabra toh, (quiché), se asocia también con el agua: Brasseur de Bourbourg la traduce como "aguacero". Toh significa "trueno"; y Tohil es el dios quiché del trueno. Por otro lado y aunque sólo 
es una coincidencia, la raíz toh (quiché) se relaciona con la raíz tun (yucateco), que significa jade. (Thompson, 1971: 78).

Otra referencia al venado en el Popol $V u h$, es la concerniente al nombre del dios XBalanqué, de $x$ prefijo femenino, balam, jaguar y ke, venado. Se trata de un dios solar, cuyo nombre, según Edmonson, significa Jaguar-Venado (Edmonson, 1971: 34).

En los Anales de los Cakchiqueles, se dice que se ponían ofrendas de venado y miel al dios Tohil, sobre todo en las ocasiones en que se quemaba el monte para preparar la siembra. Tohil es el dios de la tormenta (Recinos, 1950: 57-69). Durante la danza del venado, Edmonson refiere que este animal se convertía en el símbolo público de la tormenta (Edmonson, 1971: 186). Lo anterior nos recuerda una vez más que entre los nahuas el venado es el símbolo de la lluvia. (Spranz, 1973: 462).

Los quichés eran conocidos como Ah quelay, de que venado y hay, casa, "los señores de la Casa de los Venados", pero este título se refiere a un linaje (Recinos, 1970: 71).

\section{Dioses relacionados con el venado entre ciertos pueblos} mayas contemporáneos

Entre los espíritus guardianes que protegen a los mayas de Quintana Roo en sus actividades cotidianas, están los Balamoob o jaguares, que se manifiestan en forma de gigantes o de enanos. Los Balamoob, son los señores que cuidan de los bosques y se llaman también Kuil Kaxoob, (dioses de los bosques). Entre ellos se encuentra Yum Kaax, cuyo papel es proteger al bosque y a los animales que habitan en él.

En Yucatán existen santos católicos protectores de los animales, como son: San Gabriel, San Cecilio, San Marcelino y San Jorge. Este último es el protector de los venados (Villa Rojas, 1961: 71); pero en el pueblo de Chan Kom, (Yucatán), se cree en un ser sobrenatural protector de los mismos, llamado Zip. Este ser es un ciervo pequeño, inmaculado, con cuernos poco desarrollados y que lleva, según la creencia mítica, un nido de avispas entre sus cuernos. El cazador debe protegerse del Zip, para no fracasar en la cacería, con un talismán "de venado", que se puede encontrar en los intestinos del animal y que consiste en una formación calcárea. El talismán sólo tiene poder durante un año; pero si el cazador abusa de él, podría ser castigado por el Zip (Villa Rojas, 1961: 71). 
El Zip se puede matar mediante un secreto, que consiste en preparar un manjar con los restos del algodón que se encuentra en las madrigueras de algunos marsupiales. Con este material y hojas secas se hace una mezcla en forma de bolita que se coloca en la escopeta; pero los indígenas prefieren no acudir a esța brujería, ya que temen que el Zip desate la furia del "Espíritu de los vientos" que trae consigo (Villa Rojas, 1945: 97).

En Yucatán hay dos clases de cacería; una llamada Ppuj que es de carácter comunal y otra llamada Chuuc que se practica individualmente. La cacería Ppuj o "clamoreo" se efectúa con diez hombres aproximadamente y consiste en gritar corriendo en círculo para asustar al venado y acorralarlo. Cuando éste se encuentra cerca del hombre encargado de disparar, es fácil matarlo. Tal forma de cacería se utiliza para cobrar venados durante ciertas festividades; pero resulta peligrosa ya que pueden confundirse los hombres con los animales y siempre que se practica hay accidentes. Precisamente en la ceremonia denominada Chac Chac, que se celebra para pedir agua a los dioses de la lluvia, se utiliza esta forma de cacería. Según los indígenas, se mata a un venado "porque a los dioses les gusta su carne". El sacerdote o Ah Kin, pide permiso al Zap para cazar los ciervos necesarios para la fiesta. El sacerdote le ofrece al Zip zacá, que es una hierba asociada con esta deidad. La voluntad del Zip es conocida por el sacerdote mediante un cristal sagrado llamado zastun; además, puede mirar en él, el lugar donde se encuentran los venados. La otra forma de cacería llamada Chuuc o "espiar", la efectúa el milpero sin compañía y durante la noche. Por lo general lleva una luz que atrae al venado y así le es fácil dispararle (Villa Rojas, 1961: 96-97).

En otros pueblos mayas, también se cree en los protectores de los animales: en Chiapas, por ejemplo, los tzotziles veneran a un dios de los cerros, "Dueño de la lluvia y de la vida animal de las montañas", este se llama Anhel y es el padre de la doncella del maíz (Guiteras, 1961: 43-48). En Zinancantan, Chiapas, Yahval Balamil es el "Dueño de la. Tierra"; posee riquezas y ganado; cualquier hundimiento en la tierra sirve para llamarlo. Gobierna todos los productos del campo, así como las nubes y el rayo, monta un venado con dos iguanas por espuelas y utiliza un látigo en forma de serpiente (Vogt, 1973: 15-16).

En Chimaltenango, Guatemala, Wagley habla de la creencia de sus habitantes en los "Guardianes de los cerros". Entre estos está Tui Pich Jup, que castiga a los hombres que cazan venados sin su 
autorización. Quienes cometen este pecado, son conducidos por Tui Pich Jup a una barranca en la que tienen que trabajar como esclavos. El guardián de dichos animales se describe como un caballero español, cubierto de pieles de venado virgen (Wagley, 1959: 187). esto relaciona al protector del venado con el carácter inmaculado del Zip maya-yucateco.

Los chortís de Guatemala creen en un dios dual venado. El dios protege a los machos y la diosa a las hembras. Esta divinidad vive en las colinas donde se le ofrece copal para cobrar buenas piezas de cacería (Thompson, 1970: 309).

Los chortís de Guatemala usan una bala de plomo "curada" para cazar venados y coyotes. $\mathrm{La}$ "curación" consiste en hacer una cruz en el plomo con el filo de un cuchillo. La cacería del venado se realiza durante la noche y en ella intervienen aproximadamente doce hombres. La ceremonia de ofrecer copal sólo se celebra para cazar venados. El animal es acorralado por los cazadores mediante antorchas, ya que el fuego le produce cierto encantamiento que hace que se atonte; pero antes de salir de cacería, el cazador debe tener un sueño en el cual el protector del animal le indica un precio, pues la pieza debe ser comprada. El precio se paga con copal y éste se quema. La noche siguiente, después de puesta la ofrenda, el cazador sale a la colina y pide permiso al protector del venado para cazar. También le pregunta cuántos venados puede atrapar. Mientras los hombres van a la cacería, las mujeres ofrecen copal rezan y encienden velas. Cuando los hombres han cobrado la pieza, gritan desde un kilómetro atrás a sus mujeres, transmitiéndoles la noticia; entonces ellas queman más copal. Si el venado es hembra se le pone un sombrero de hombre y si es macho un chal de mujer. El humo del copal purifica el cadáver del animal y expulsa a los malos espíritus. Los cuernos del venado se cuelgan y se guardan para tener buen éxito en otras cacerías. (Wisdom, 1961: 94-8).

En el territorio quiché y kekchí de Santa María de Jesús en Guatemala existe una cueva donde los indígenas almacenan cráneos de venados cazados (Termer, 1957: 161). Probablemente estos animales tengan un carácter sagrado.

Los tzutujiles de San Pedro de La Laguna, Guatemala, creen que el Sol cruza el cielo montado en un venado durante los días cortos del año (Thompson, 1939: 150). Lo anterior recuerda la asociación que existe entre el venado y el dios solar.

En Guatemala es famosa la danza de los animales en la cual un personaje asume el papel de venado, lamentándose de que a todos 
les guste el sabor de su carne. Pero durante la danza revela que se entrega con júbilo al sacrificio. El venado es considerado siervo de Dios, siendo el que le informa la maldad de los hombres (Termer, 1957: 257-68).

En Belice, mopanes y kekchíes veneran a Xulab u "Hormiga Gigante"; personaje que es el "Dueño de los animales" y que se identifica con el planeta Venus considerándosele hermano del Sol.

Los cazadores deben guardar vigilia, abstinencia sexual y ofrecer copal a Xulab para que este les conceda buenas piezas de cacería. Cuando se invoca a Xulab se le denomina "Espíritu de las milpas", "Señor de los montes y colinas" o Huitz Hok, "Protector de las cosechas y de la pesca" (Thompson, 1930: 88-9).

\section{Conclusiones}

Como hemos podido apreciar, el venado en la cultura maya jugó un papel muy importante en relación con varios aspectos de las creencias religiosas.

La cacería y el sacrificio del venado han quedado grabados en las representaciones iconográficas de muy diversos materiales arqueológicos; por otra parte, tanto en las fuentes de la historia maya como en los datos de la etnografía moderna, encontramos explicaciones precisas sobre el sentido religioso de tales faenas.

El venado fue tenido también como un ser que desempañaba la función de intermediario entre los hombres y las divinidades. Una prueba de ello es la representación que vemos en el monolito de Cotzumalhuapa, Guatemala; en el cual aparece un venado en actitud de entregar a una deidad el símbolo de un corazón sacrificado. En Guatemala, hoy en día los indígenas consideran que el venado habla con los dioses para delatar los pecados de los hombres.

Como símbolo esotérico, encontramos una cabeza de ciervo modelada en un pedazo de estuco, que posee la particularidad de tener la huella de la planta de un pie humano en el lugar de uno de los ojos. La cabeza proviene de la azotea del Templo de las Incripciones de Palenque.

Por otra parte, el venado ha sido y es para los mayas el símbolo de la lluvia y de la fertilidad, siendo su cuerpo un objeto sagrado que propicia tales fenómenos, en los códices aparecen ofrendas de venados expuestas a los dioses para rogarles que venga la lluvia nenecesaria para las cosechas. El dios B (deidad de la lluvia y la fertilidad) se halla relacionado con las ofrendas de venado; $\mathrm{e}$ inclusive 
se le pinta montado sobre el animal. El sentido de la relación del dios $\mathrm{B}$ con el venado en este caso es doble: por un lado alude a la lluvia y por el otro representa la sequía que amenaza las cosechas. La relación del venado con la lluvia también se expresa en el Popol $V u$ ih de los quichés, y en los Anales de los Cakchiqueles; donde leemos que Tohil, deidad de la tormenta, se representaba con la piel de un venado.

El fenómeno periódico del cambio de su cornamenta y su relación con la renovación anual de los cultivos, es otra asociación de carácter mágico que se atribuyó al venado debido a sus cualidades intrínsecas. Lo anterior se encuentra obviamente expresado en el grabado del plato policromado de Calcehtok, Yucatán.

El Códice Madrid muestra el sacrificio de un venado mediante la picadura de un alacrán; tal vez su sentido sea expresar un "sacrificio preciso y penoso". Esto nos recuerda la idea muy difundida entre los mayas de Yucatán, de que el venado debe morir llorando porque sus lágrimas propician la lluvia.

Después de lo anterior no es posible negar la afinidad que existe entre el venado, su sacrificio ritual y la renovación de las plantas; pero el problema se complica más si advertimos que los dioses de la lluvia y la fertilidad propiamente dichos se encuentran asociados a su vez con la cacería y la protección de los animales. Veamos a continuación algunos ejemplos: en el Códice de Dresde el dios B (deidad de la lluvia y la fertilidad) aparece con las cuatro ofrendas principales destinadas a solicitar buenas piezas de cacería, relacionándose de esta manera con la actividad venatoria. En el caso de los mayas de Yucatán, la conexión entre los dioses de la fertilidad y los patrones de la cacería no es fácil de comprobar; sin embargo, presentamos algunos argumentos al respecto. Landa refiere que durante las ceremonias de los cazadores, efectuada el día Siete Zip, estaban presentes los dioses Itzamná, Ixchel, Acanúm, Zuhuyzib y Zipitabay. Itzamná es una deidad muy compleja, pero con el nombre de Itzamná T'ul representa al señor de la fertilidad. (Thompson, 1975: 262). Ixchel, es la diosa de los nacimientos y del tejido, consorte de Itzamná y representante de la fecundidad femenina en el corpus de los mitos mayas. Acanúm, Zuhuyzib y Zipitabay son, según Landa, los dioses patrones de la cacería, pero el hecho de que todos estos dioses estuviesen juntos en la ceremonia nos autoriza a pensar que había cierta afinidad entre ellos. Al menos Zipitabay, nombre que significa "La que concede dones mediante mecates" parece tener relación con la denominación de la diosa Xtabay, patrona de los que mueren ahor- 
cados. A su vez, Xtabay parece ser una advocación de Ixchel, por la relación que ambas tienen con el tejido.

Landa consideró a Itzamná e Ixchel dioses creadores y patrones de la medicina; aunque no es difícil pensar que alguna vez fuesen dioses de la cacería. Esta hipótesis puede apoyarse en las teorías de Jensen, quien afirma que en la época en que los hombres se dedicaban a las actividades de cacería como fuente principal de subsistencia, los dioses creadores eran vistos como patrones de tal actividad; pero cuando los hombres comenzaron a practicar la agricultura, las deidades de la cacería quedaron reducidas a meros espíritus guardianes de bosques y animales. Los dioses creadores por su parte, se mantuvieron como tales cumpliendo sus funciones específicas. (Jensen, 1966: 163). Posiblemente esto sucedió con Itzamná e Ixchel, quedando como patrones de la cacería en aquel tiempo Zuhuyzib y Zipitabay, de quienes proviene el Zip de nuestros días.

Entre los mayas actuales, los dioses de la lluvia y los patrones de los animales no se encuentran diferenciados completamente. En Yucatán, el protector de los venados denominado Zip; es considerado el "Espíritu de los Vientos" que habita en cuevas y ojos de agua. Precisamente en estos lugares suelen celebrarse ceremonias enminadas a la petición de las lluvias. Además, durante la ceremonia denominada Chac Chac, que se efectúa por igual motivo, se sacrifica un venado. En Chiapas, el "Dueño del ganado", posee poderes para dominar el rayo las nubes, y en Belice, Xulab, el "Protector de los animales", es a la vez protector de la pesca y la agricultura; lo cual lo relaciona con el agua.

$\mathrm{El}$ dios $\mathrm{R}$ estudiado por Thompson se presenta en los calendarios y en los augurios de los días relacionado con el monte, la cacería, los animales y el maíz. Sin embargo en el caso de esta deidad, no poseemos datos precisos para caracterizarla como patrona del viento o la lluvia, a pesar de que se trata de un dios asociado con las montañas.

Conviene señalar por otra parte, algunas similitudes que presentan los dioses patrones de la cacería en el antiguo Yucatán y el Zip contemporáneo. Acanúm, Zuhuyzib y Zipitabay son las deidades patronas de la actividad venatoria mencionadas por Landa; Ah Uuc Yol Zip e Ix Mekla Zib son las que describe Roys en el Ritual de los Bacaboob. Acanúm, "El que gime o brama" y Zuhuyzib, "El que es virgen y concede dones"; evocan las características del actual protector de los venados donominado Zip por los maya yucatecos y al cual Villa Rojas describe como un ciervo pequeño, inmaculado, 
relacionado con el viento. Además, dicho autor menciona también la creencia popular que perdura en Chan Kom, Yucatán, en cuanto a que el Zip "gime" y "brama" para avisar a sus congéneres que los cazadores se acercan (1961: 71). Debido a lo anterior, me inclino a pensar que el Zip contemporáneo es una superivivencia del dios prehispánico Zuhuyzib; siendo Acanúm y Zuhuyzib dos diferentes denominaciones de la misma deidad patrona de la cacería.

Sin embargo, no poseemos pruebas para afirmar que Zuhuyzib haya sido, en la época prehispánica, un protector específico del venado, ya que Landa sólo menciona a este tipo de deidades como patronos de la cacería. Empero, es muy posible que hayan existido protectores especializados de los animales por dos razones: una, y en è caso del venado, debido a que este animal constituía la principal ofrenda para el culto a los dioses, según puede observarse en los códices. La cacería del venado, por este motivo, debió ser excesiva y la necesidad de un protector específico de los ciervos muy obvia.

Otrà razón es que en Yucatán aún se cree en diversos seres protectores de los animales, los cuales suelen confundirse con los santos católicos. Estos seres son sin duda sobrevivencia de antiguos dioses, entre los cuales pudo existir el protector especial de los venados.

El protector de los animales desempeña un papel fundamental en la cultura puesto que constituye un elemento ideológico que permite ejercer control sobre la devastación de la riqueza animal de los bosques.

Volviendo a los dioses patronos de la cacería, notemos que Ah Uuc Yoy Zip, "Señor Siete Corazón Ofrenda" e Ix Mekla Zib, "La que porta las ofrendas" parecen ser dos denominaciones de este tipo de dioses. Siete Corazón Ofrenda, al menos, tiene cierta afinidad con el nombre del día Siete Zip, durante el cual se efectuaba la fiesta de los cazadores. Zipitabay "La que concede dones mediante mecates"; (deidad que parece ser patrona de las trampas para cazai venados) e Ix Mekla Zib, "La que porta las ofrendas"; son a su vez dos divinidades, en apariencia femeninas, posiblemente consortes de los respectivos dioses de la cacería mencionados por Landa y por Roys. Lo anterior no es difícil de deducir si recordamos la dualidad cáracterística de los dioses mesoamericanos; sin embargo, no poseemos datos suficientes para sostener esta afirmación de manera definitiva.

Es probable que la apariencia de los dioses patronos de la cacería fuese concebida en forma de venado. Los nombres de algunos parecen indicarlo; por ejemplo, "El que gime o brama", mencionado por Landa, el "Señor de los Venados", descrito por Bernal Díaz con 
aspecto de dicho animal o el propio Zip maya yucateco, estudiado por Villa Rojas. El dios $\mathrm{R}$ descrito por Thompson que resulta ser protector de la fauna, se relaciona también estrechamente con el venado.

Por otra parte, los dioses $\mathrm{L}, \mathrm{M}$ y $\mathrm{Q}$ se relacionan con el venado, la cacería y la protección de los animales de la siguiente manera: la deidad L estudiada por Thompson, semeja ser una manifestación terrestre del dios Venus; aunque no se relaciona directamente con el venado, está asociado al monte y a los animales que allí habitan. Lo anterior se hace más preciso con el hecho de que en Belice, el protector de los animales es Xulab a quien se le identifica con dicho planeta.

El dios de la guerra (M) se conecta con el venado y la cacería porque aparece en el Códice Madrid con atavíos de cazador y con un tocado en forma de venado. Eventualmente esto se explica debido a que en Mesoamérica las actividades bélicas tienen evidente afinidad con las venatorias y en ocasiones los dioses representantes de ambas, comparten sus atributos.

El dios de los sacrificios $(Q)$ se halla asociado al venado ya que tanto él como la deidad de la muerte, suelen estar presentes en las ceremonias de inmolación del venado.

Así es como el venado en la cultura maya se ha convertido en el símbolo de las actividades sagradas de la cacería, el sacrificio y la muerte ritual y en la representación del espíritu del viento que habita las montañas y transporta la lluvia. Su cuerpo se considera desde tiempos remotos un objeto para propiciar la fertilidad y la abundancia y su imagen benévola evoca la figura de los dioses del monte, dueños de los animales y patronos de la cacería.

\section{BIBLIOGRAFIA}

\section{Alctina Franch, José}

1957 Floresta Literaria de América Indígena (Antología). Editorial Aguilar, Madrid.

\section{Anton, Ferdinand}

1968 Art of the Maya. Thames and Hudson, London, 344 pp. con 365 ilustraciones.

\section{Barrera Vázquez, Alfredo}

1965 El libre de los cantares de Dzibalché. I.N.A.H. No. 9, México. 
Bunzel, Ruth

1967 Chichicastenango a Guatemala Village. University of Washington, Seattle and London, $438 \mathrm{p}$.

Códíce Dresde

1962 Codex Dresdensis: die maya-Handschrift in der sachsischen Landesbibliothec Dresden. Vorwort E. Lips (Berlín).

CódIce Pérez

1949 Traducción libre del maya al castellano por el Dr. Emilio Solís Alcalá, Mérida, Yuc. México, 371 pp.

Códice Peresianus

1968 (Codex Paris) Biblioteca Nacional de París. Einleitung und summary. F. Anders. Akademische Druck-u. Verlagsanstalt Graz-Austria.

Códce Tortesianus

1967 (Codex Madrid) Museo de América, Madrid, Einleitung und summary. F. Anders, Akademische Druk-u. Verlagsanstalt Graz-Austria.

Edmonson, Munro S.

1965 Quiche-English Dictionary. Tulane University, Middle American Research Institute, Pub. No. 30, New Orleans.

1971 The Book of Counsel; The Popol Vuh of Quiche Maya of Guatemala. Pub. No. 35 Middle American Research Institute, Tulane University, New Orleans.

Enciciopedia Yucatanense

1945 Patrocinada por Ernesto Novelo Torres, Tomo I, Yucatán.

Fuentes y Guzmán, Antonio

1932 Recordación florida. Discurso historial y demostración natural, material, militar y política del reino de Guatemala. Prólogo de J. A. Villacorta, Ramón A. Salazar y Sinforoso Aguilar. Biblioteca de Guatemala de la Sociedad de Geografía e Historia, Vols. VI-III, Guatemala.

Morley Sylvanus G. y George W. Brainerd

1972 La civilización maya. Fondo de Cultura Económica, México.

Pendergast, David M.

1966 Sobretiro de Archaeology, V. 19, m. 3, p. 154-161.

Roys, RALPH

1967 The book of Chilam Balam of Chumayel. University of Oklahoma Press, Norman, 229 pp. 
Ruz Lhumlier, Alberto

1956 "Exploraciones arqueológicas en Palenque" en Anales del INAH, Tomo X, pp. 241-299.

\section{Schellmas Paul}

1904 "Representations of Deities of the Maya Manuscripts" en Papers of Peabody Museum of American Archaeology and Ethnology. Harvard University, 2a. Ed. Cambridge Mass. Published by the Museum.

SHaW Mary

1972 Según nuestros antepasados... Textos folklóricos de Guatemala y Honduras. Redactora: Mary Shaw, Artista: Patricia Ingersoll. Instituto Lingüístico de Verano en Centroamérica. Guatemala, 502 pp.

Spranz, Bodo

1973 Los dioses en los códices mexicanos del grupo Borgia. Editorial Fondo de Cultura Económica, México, 517 pp.

Soustelle, Jacques

1959-61 El pensamiento cosmogónico de los antiguos mexicanos. Federación estudiantil poblana, México.

Termer, Franz

1957 Etnología y Etnografía de Guatemala. Seminario de Integración Social Guatemalteca, Guatemala, 299 pp.

Thompson, J. ERIG

1930 'Ethnology of the Mayas of Southern and Central British Honduras" en Field Museum of Natural History, Pub. 274, Anthropological Series, Vol. XVII, No. 2, Chicago, 187 pp.

1939 "The Moon goddness in Middle America" (With notes on related deities) En Contributions to American Anthropology and History No. 29, Serie 22-29 Junio, pp. 122-73.

1963 Maya Archaeologist, Londres, Robert Hale Limited, 208 pp.

1970 Maya History and Religion. University of Oklahoma Press, Norman, 415 p.

1971 Maya Hierogliphic Writing. University of Oklahoma Press, Norman, $349 \mathrm{pp}$. (con un apéndice sobre glifos).

Tozzer, Alfred and Allen Glover M.

1910 "Animal Figures in the Maya Codices" en Papers of the Museum of American Archaeologist and Etnology; Harvard University, Vol. IV, No. 3, Cambridge, pp. 272-372.

1941 Landa's Relación de las cosas de Yucatán. Ed. por Tozzer en Papers of the Peabody Museum of American Archaeology and Ethnology, Harvard University, Cambridge, 394 pp. 
Villa Rojas, Alfonso

1945 "The Maya of East Central Quintana Roo" en Carnegie Institute of Washington. Pub. No. 559; Washington, D. C.

1961 Los mayas de las tierras bajas. Guión presentado al Consejo de Planeación e instalación dẹl Museo Nacional de Antropología INAH, CAPCE, SEP, México, 128 p.

1962 "Los Quejaches: Tribu olvidada del antiguo Yucatán" en Revista Mexicana de Estudios Antropológicos; Tomo XVIII, 97-117 pp.

Voct, Evon Z.

1973 Los zinacantecos, un grupo maya en el siglo XX. Colección Sep-Setentas, Sría. de Educación Pública, México, 175 p.

Wagley, Charles

1957 Santiago Chimaltenango. Seminario de Integración Social Guatemalteca, Guatemala, 399 pp.

Wisdom, Charles

1961 Los chortís de Guatemala. Seminario de Integración Social Guatemalteca, No. 10, Guatemala. 